\title{
Optimal Combustion Conditions for a Small-scale Biomass Boiler
}

\author{
Viktor Plaček ${ }^{1}$, Cyril Oswald ${ }^{1}$, Jan Hrdlička² \\ ${ }^{1}$ Czech Technical University in Prague, Faculty of Mechanical Engineering, Department of Instrumentation and Control \\ Engineering, Technická 4, 16607 Prague 6, Czech Republic \\ ${ }^{2}$ Czech Technical University in Prague, Faculty of Mechanical Engineering, Department of Power Engineering, \\ Technická 4, 16607 Prague 6, Czech Republic
}

Correspondence to: viktor. placek@fs.cvut.cz

\begin{abstract}
This paper reports on an attempt to achieve maximum efficiency and lowest possible emissions for a small-scale biomass boiler. This aim can be attained only by changing the control algorithm of the boiler, and in this way not raising the acquisition costs for the boiler. This paper describes the experimental facility, the problems that arose while establishing the facility, and how we have dealt with them. The focus is on discontinuities arising after periodic grate sweeping, and on finding the parameters of the PID control loops. Alongside these methods, which need a lambda probe signal for proper functionality, we inroduce another method, which is able to intercept the optimal combustion working point without the need to use a lambda sensor.
\end{abstract}

Keywords: biomass, combustion, control.

\section{Introduction}

Small-scale boilers used for residential heating have undergone considerable development in the last decade. The developments have focused on reducing manual user handling. This has led to the requirement for a low-volume fuel that can be delivered to the boiler by automatic feeding. Automatic feeding enables the fuel to be fed in smaller batches, so that the combustion process is disurbed much less than when the fuel is stoked in the form of whole logs. Feeding small batches also allows combustion in much smaller combustion chambers, so that the size of the boiler can also be reduced [5].

However, a smaller combustion chamber leads to issues with combustion process control. The small mass of the burning fuel leads to much faster dynamics of the combustion process response, requiring the controller parameters to be more carefully adjusted for faster reactions. Other differences between smallscale boilers and larger boilers are:

- not only faster but also more sensitive to external influences,

- are more resistant to lack of maintenance of the boiler,

- sensors are not periodically tested.

We are developing a new original algorithm to control the combustion process in a way that will maintain the combustion process in optimal conditions. The algorithm meets the requirements of low acquisition costs and takes advantage of the sensitiv- ity of the combustion process to external sources of excitation. It is also resistant to qualitative changes in the combustion process due to lack of maintenance. The combustion process is often controlled by maintaining an optimal air-to-fuel ratio using feedback from a lambda probe (more on this topic in [5]). Although a lambda probe is not expensive equipment nowadays, it still has significant impact on the cost of automating a boiler. The proposed algorithm is able to find the optimal air-to-fuel ratio without the need to use a lambda probe.

\section{Experimental arrangement and deployment}

The basic arrangement used for combustion control of small-scale biomass boilers is depicted in Figure 1. It is based on a biomass boiler for residential and small enterprise heating that is widely available on the market. Its warmed water heat output is $25 \mathrm{~kW}$ when combusting wood pellets. The original control electronics for the boiler was purpose-made, and could not be used for experimental control. We therefore developed and installed a control unit in addition to the original control electronics. The control unit is based on the RexWinLab-8000 data acquisition and control station, which had earlier been developed at the department where the authors work. Further information on the control unit can be found in [3]. 


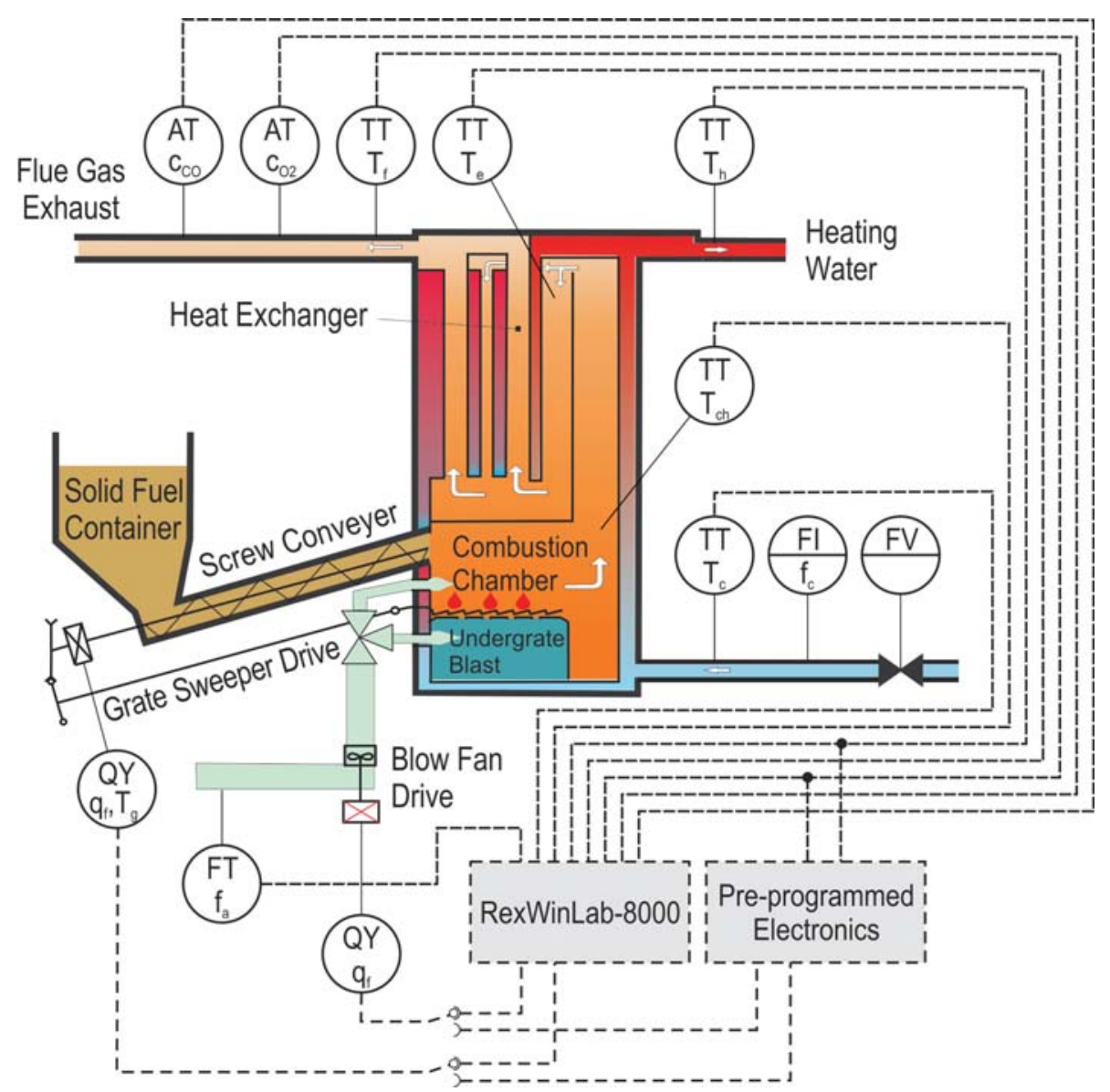

Figure 1: Process schematic of adapted boiler used for small-scale experiments

The boiler instrumentation was further extended by thermal measurements, a flue gas analyzing unit, a frequency changer for combustion air speed control, etc.

The first issue that emerged when we completed the experimental arrangement was that we observed quite strong peaks in $\mathrm{CO}$ emissions in instants just after grate sweeping. According to [1], these peaks are probably caused by the formation of air channels in the burning layer of the biomass which are destroyed by movement of the whole layer during grate sweeping. Until new channels are established, the combustion is temporarily short of oxygen. We shortened the length of the grate-sweeper run and shortened the grate sweeping period accordingly. The tuned grate sweeping algorithm led to almost complete elimination of the $\mathrm{CO}$ peaks. More on this topic can be found in [3].

The original control electronics of the boiler uses some proprietary modulation of the heat output that is unknown to us. The modulation is based on burn out and start up of the fire in the combustion chamber, leading to quite long transitions. During the transitions, the boiler has considerably high emissions of flue gases, and as in the case of the grate sweeping peaks mentioned above, unpleasant fluctuations make any automatic evaluation of the steady state of the combustion process difficult.

\section{Optimizing the operation conditions for a small-scale biomass-fired hot-water boiler}

The optimal operation conditions for a biomass-fired boiler can be viewed from two main perspectives: economic, and ecological. From the economic point of view, we want to maintain the desired performance of the boiler while using as little fuel as possible. In other words, we want to achieve maximum boiler efficiency. From the ecological point of view, we want to have the lowest content of monitored components in the flue gases throughout the process.

Both the economic aspects and the ecological aspects of optimal combustion can be affected by controlling the current excess air ratio. If the only ecological consideration is to monitor carbon monoxide 
emissions, both of the combustion optimality requirements can be fulfilled at very similar excess air ratio values (Figure 2). Then the optimal operation conditions for a biomass-fired boiler can be achieved by monitoring only a single factor.

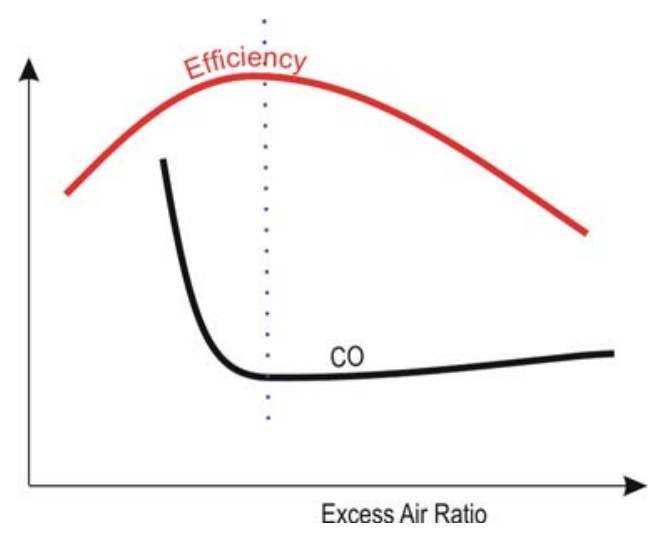

Figure 2: Efficiency and CO dependency on excess air ratio for a biomass combustion process - a typical trend scheme demonstrating that the minimum of $\mathrm{CO}$ emissions and the efficiency maximum occur for approximately the same excess air ratio value

A typical approach to controlling the optimal operation conditions for a biomass-fired boiler involves monitoring the current carbon monoxide content in the flue gases and controlling the excess air ratio by changing the primary and/or secondary combustion air supply. This approach is effective and relatively fast. On the other hand, optimizing the boiler operation conditions by analyzing the composition of the flue gases requires special, relatively expensive instrumentation such as a lambda probe. The additional expenses are problem for producers of smallscale biomass-fired boilers for residential heating, and for their customers.

The control algorithm for optimizing small-scale biomass-fired boiler operation conditions by monitoring current fuel consumption has been developed for this reason. The new optimization algorithm is based on the following assumption: if the controller continuously controls the current boiler heat output by changing the fuel supply, and there are no changes in the desired boiler heat output, then the maximum boiler efficiency is achieved when the fuel consumption is lowest.

The proposed algorithm continuously analyzes current fuel consumption and adjusts the combustion air supply to achieve the minimum required fuel consumption by changing the excess air ratio. This approach is more time consuming than the approach using an analysis of the fuel gases. On the other hand, the proposed optimization algorithm does not need special additional instrumentation, and does not introduce any additional costs for the boiler producer. The proposed optimization algorithm was tested on the small-scale biomass-fired boiler introduced above. The results of the test are depicted in Figure 3. It shows that, although this approach is very time-consuming, it is an effective and cheap way to find and maintain small-scale biomass-fired boiler combustion in its optimal operating conditions.

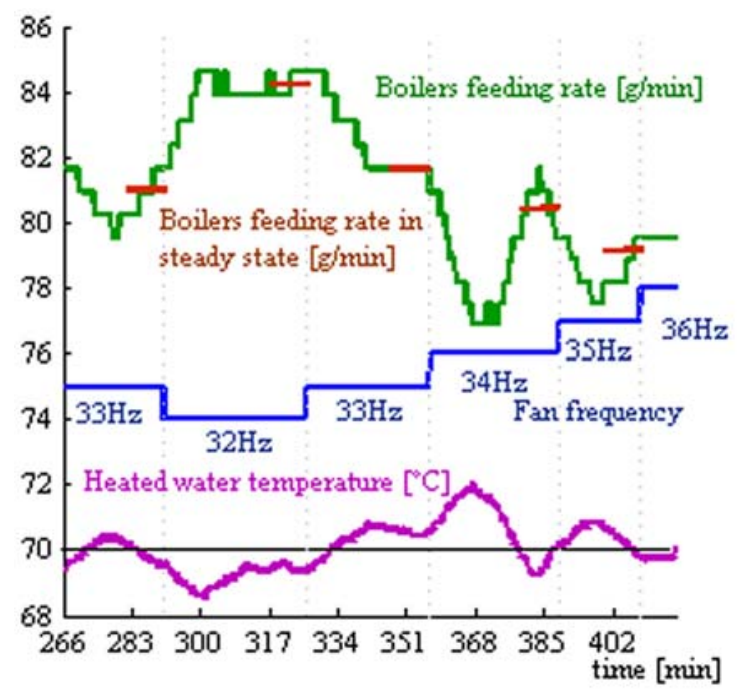

Figure 3: Results of a air-fuel ratio optimization algorithm experiment

We are currently developing the optimization approach for mid-scale boilers, which will use a combination of the two approaches mentioned here to achieve a better compromise between the two aspects of optimal operating conditions. In addition, this new approach should be able to observe the current combustion process parameters.

\section{Conclusion}

Although there are no emission regulations for smallscale boilers in most countries, recent developments in national legislation show that this situation will probably change in the near future. One probably inevitable way to reduce emissions will be by improving boiler control algorithms. This paper has pointed out some of the issues that can arise when building an experimental small-scale biomass combustion platform. It has also introduced a method for finding optimal combustion conditions without the need for a lambda probe.

Future work will involve testing the proposed algorithm on a boiler with a much greater heat output. The Verner 600 experimental boiler is located in Turňa nad Bodvou in Slovakia, and experiments 
on it are controlled remotely, using the Internet, in cooperation with Technical University in Košice.

\section{Acknowledgement}

This work has been supported by the Ministry of Education of the Czech Republic, under project No. MSM68400770035 "Development of environmentally friendly decentralized power systems", which is gratefully acknowledged.

The work of PhD students has been supported by Doctoral Grant Support of the Czech Technical University in Prague, grant No. SGS10/252/ OHK2/3T/12.

\section{References}

[1] Korpela, T., Bjorkovist, T., Lautala, P.: Durable feedback control system for small scale wood chip combustion. In Proceedings of World Bioenergy 2008, Jönköping, Sweden : May 2008, p. 224-230.

[2] Mižák, J., Pitel', J. On the problem of use of Lamda sensors for combustion control. In Zbornik príspevkov ARTEP 2011, Stará Lesná,
16. 2.-18. 2. 2011. [CD-ROM]. Košice : TU v Košiciach, 2011. ISBN 978-80-553-0606-3.

[3] Plaček, V., Šulc, B., Vrána, S., Hrdlička, J., Pitel', J.: Investigation in Control of Smallscale Biomass Boilers. In Proceedings of the 2011 12th International Carpathian Control Conference (ICCC), Velké Karlovice : IEEE - Systems, Man, and Cybernetics Society, 2011, p. 312-315.

[4] Oswald, C., Šulc, B.: Achieving Optimal Operating Conditions in PI Controlled Biomass-fired Boilers: Undemanding way for improvement of small-scale boiler effectiveness. In Proceedings of the 2011 12th International Carpathian Control Conference. Velke Karlovice : 25.-28. May 2011, p. 280-285. ISBN 978-1-61284-359-9.

[5] Pitel', J., Mižák, J.: Approximation of CO/ lambda biomass combustion dependence by artificial intelligence techniques. In Annals of DAAAM for $2011 \&$ Proceedings of the 22nd International DAAAM Symposium, Vienna : DAAAM International, p. 0143-0144.

[6] van Loo, S., Koppejan, J.: The Handbook of Biomass Combustion and Co-firing. London : Earthscan, 2008. 